\title{
Educating First and Third World Development Planners: The Role of Qualitative Evaluations
}

\author{
Hemalata C. Dandekar \\ University of Michigan
}

\section{FIRST ENCOUNTERS}

I was introduced to Dominick's café as a student in 1968. The Department of Architecture, at The University of Michigan, where I had just enrolled for graduate work, was at that time housed in the building that stands across from the café. My advisor, Steve Paraskevopoulos, had taken me there to begin my orientation to higher education in the United States. I had never been given this much attention by any faculty member during my five years of undergraduate life at the University of Bombay, not even when I received prizes - and I had won all the ones offered in the College of Architecture - nor when I graduated at the top of my class in the university.

The offer of a fellowship from the Department of Architecture at Michigan had made possible my presence in the US. It was unusual for departments to give financial aid to new foreign students, even in the sixties when money for such largesse was less scarce. I was well aware of this and knew that "they" were taking a chance with me. So I sat before Steve, with little financial backing from home, obviously anxious. I had arrived very concerned, at best, about doing well at school, or, at the very least, not failing to meet the academic standards that would be expected of me. I suspect that Steve's Greek origin, his constant journeys back and forth between the two cultures (he spent the academic year in Ann Arbor and summers in architectural practice in Athens), enabled him to realize some aspects of my psychological state and the sobering facts of my somewhat precarious material condition.

Sizing up the situation, Steve tried to alleviate my fears across various parameters, "You seem to speak English," he said, as if that itself were a significant achievement. "Want to be a teaching assistant for design and visuals?" (The war in Vietnam had reached into Ann Arbor and the American student who had originally been awarded this position, poor man, had been drafted.) Of course I did not! In my most insecure moments, and there had been many in the few 
weeks since I had landed on these shores, my sights were set on merely surviving academically at the school. The assistantship meant financial security, my own apartment, a new wool coat. But to teach design! To complicate matters I didn't even know what he meant by visuals. Nationally specific professional jargon complicated the communication. I would have been comfortable if he had asked me to teach technical subjects like structural engineering, drafting, or material testing. I knew I had learned those skills well enough at home in Bombay. But for someone in my financial predicament it was impossible to turn down this offer, "Yes, of course, I want to be a teaching assistant; I am sure I can do the job," I said; whatever it is, I thought, swallowing hard.

I was a success as a teaching assistant and, more significantly, found I enjoyed the experience. It was an experience I had not consciously identified as something I would strive for during my graduate studies in the US. The opportunity that Steve so casually threw into my lap that afternoon at Dominick's allowed me to discover that I could teach. I had never taught before and in many ways this early experience set the stage for further exploration in this area, culminating in what I do today: teach for a living. I suspect that Steve had much to do with the Department's initial offer of a fellowship too. The combination of a foreign-born academic, who intuitively sensed both my uncertainty and potential, and an institution willing to heed his judgment of an unknown foreign student provided an opportunity for growth that was critical to my professional, and indirectly my personal, development.

A touching story, the reader might be thinking, but what does this have to do with the subject at hand - qualitative evaluations in development planning? There is indeed a significant connection. I believe that effective teaching of Third World students (and perhaps all students at the graduate level) requires a qualitative approach on the part of the faculty person and an ability to understand this approach and respond to it on the part of the student. A qualitative approach is essential I believe because graduate studies at their best, rather than being primarily technical skill building endeavors, are exercises in developing the students' powers of interpretation and their ability to establish new and thoughtful interrelationships between facts and observations. Graduate study is about the making of an inquiring mind. In this effort both the student and the teacher must acquire a qualitative understanding of the other. Those who recognize that this is so from the beginning and are abie to make explicit efforts to achieve this understanding are successful whether in the role of student or of faculty.

In retrospect, I realize now that the teaching of a qualitative approach starts with the very first orientation of new students, particularly those from foreign countries. This is when the "style" of interaction and the basis for a trusting relationship between student and faculty advisor are, or are not, established, with long-term consequences for both. This is also when a frame of reference for subsequent dialogue and the sharing of discoveries begins to become apparent. The professors' internal models for perceiving the world are gradually revealed to the student and vice versa. These early conversations between professors and students 
are instrumental in establishing the intellectual approach to planning problems. This is when the initial and judicious choices between qualitative and quantitative approaches to getting to know a subject begin and a balance is struck between emphasis on techniques and methods and normative, qualitative conceptualization

In my own evolution as a graduate student and then as an academic, besides Steve Paraskevopoulos, other foreign-born professors at American universities, for example, John Friedmann who was raised in Vienna and Peter Marris from England, played a crucial role. But my point is not that academic advisors must be foreign-born to be successful in dealing with foreign students nor that such sensibilities are embodied only in academics in the US. In fact, later in this chapter I give examples to the contrary. My point is, rather, that a great deal of qualitative understanding of differing cultural contexts and people is necessary or the part of academic advisors everywhere to establish a constructive framework in which the graduate student's development can flourish. It just so happens that some of my significant academic mentors were foreign-born. I am grateful that their understanding of the academic world in the US as well as their knowledge of the Third World context in which I was raised were instrumental in catalyzing the most radical transformations in me. They are the role models that continue to help me define my responsibilities as an educator to both foreign and domestic students and inform me in my efforts to impart a one-world planning education at The University of Michigan.

In the actions of these foreign-born academic advisors, I was fortunate to experience some excellent examples of the roles professors play in the guidance of students. They demonstrated the effective teaching of research skills through establishing a personal yet professional relationship with the student. They did this by being sensitive to the characteristics of Third World people's self-perceptions that were initially reflected in my own ambivalence about my abilities. With the insight of good educators, these mentors opened my eyes to the inner workings of American academics and provided the necessary nudge I needed, both: psychologically and institutionally, to undertake various teaching and professiona! responsibilities. Understanding foreign students (in an eclectic and integrative field such as development planning, perhaps all students at the graduate level) requires a qualitative evaluation on the part of the faculty member who functions as a primary advisor.

The responsibility of establishing a qualitative approach does not rest soleiy with the professor. A qualitative understanding on the part of the student too is required for a good, productive relationship. The student who is capable of figuring out "the system" and developing a qualitative understanding of it. will be successful. However, newly arrived foreign students confront some impediments. Some generic problems arise as a result of the differences in attitudes and expectations between those that a Third World student brings to this country and those embedded in the culture of the receiving US institutions. The foreign students' internalized models of appropriate behavior in relationship to faculty and other students and the pedagogical styles to which they are acclimatized are, at 
times, in stark contrast to the choices and postures faculty and North American students find to be acceptable and that the university endorses. The foreign students' intellectual history is framed by specific culturally embedded forces such as egalitarian versus hierarchical norms of personal interaction. These are of course colored by the gender of the student too. Very different postures may be expected of male and female students from the same country. The faculty advisor's sensitivity to these differences can help the student to figure out the new system he or she is now a part of and to aid him or her to develop a different, perhaps more qualitative approach to learning to become a member of the new community.

One obvious and potentially disorienting example of differences in studentfaculty relationships in a Third World country and in the US is the informal US style of faculty- student relationship, which can be confusing and/or difficult for the foreign student to adjust to. Often in the US faculty and students, especially at the doctoral level, address each other by their first names. Faculty will host students in the intimacy of their homes. Yet the academic evaluations made of the student and the professional judgments do not reflect this social "closeness." In fact, qualitative evaluations of the students' performance and capabilities are being made in this informal context. This lack of congruence between personal and professional postures can fly in the face of operating strategies that have worked for the student in other cultures. Giving gifts as tokens of one's respect and loyalty to new "gurus," paurons, or mentors is "natural." Accepting these tokens of appreciation is an indication of commitment to the student to be manifested by taking care of the student throligh academic complexities. In contrast, the US academic often finds it awkward to receive gifts from foreign students. He or she perceives that these gifts can sometimes become bribes and is leery of the commitments that may be implied by their acceptance. Both US faculty and foreign students may need to resolve this in a mutually acceptable manner so that neither feels compromised, embarrassed or misled. This requires qualitative, interpersonal skills and the ability to meet each other on new intellectual and emotional ground.

The Third World students' attitudes and world view are also formed by the political ideology and form of government of their country of origin. They are also influenced by the student's family status and economic position in that society. This influences whether the student is committed to returning to the home country or is more interested in developing skills and contacts that will enable him or her to find a home in the host country. Students may come from societies where friendships are formed not primarily between individuals but among family members that are linked by ties of clan, caste, or economics. Thus there are often contradictions between the Third World student's mind-set and the institutional environment. If these are not explicitly addressed and resolved, various problems can arise in developing a one-world approach to planning education for developing and developed countries.

One possible area of initial friction is the concept of what constitutes learning and education in the truly excellent universities in America. To me, these universities epitomize the most promising intellectual and material infrastructure 
needed in the development of a one-world approach to education. What they offer is quite different from what is in vogue in most of Third World academia. In the Third World, activities stressed are those oriented to compilation of facts and a cataloguing and description of "the truth" as observed from a particular theoretical position. There is little questioning of the theoretical position itself, one which, unfortunately (for the purpose of "fit" and "appropriateness" to Third World contexts), is often adopted from, or primarily developed in, Western, First World academic institutes. This is not to denigrate the contributions such quantitative work in Third World countries makes to what we understand about these countries today. In fact, in India this approach can be seen as an evolution from both the Vedantic,and the British systems of knowing about the world. The Vedantic, Hindu systems of education earlier prevalent in India stressed the art of learning by memorization of appropriate and established bodies of information. The British educational system that followed was oriented to the production of efficient clerks and functionaries needed to staff the vast British bureaucracy that administered India. An educational system was developed that understressed the sciences and technical, professional fields and emphasized the liberal arts and a training that fostered systematic and careful, but uninspired, documentation and data collection. In the post-Independence, Nehru era of science-led development, only a few elite educational institutions, like the Indian Institutes of Technologies, which were established with Western collaboration, have made a dent in changing these attitudes.

In contrast to this, a questioning of the roots, the premises, the very foundations of the work is encouraged in the brasher, younger worid of the more innovative American academic institutions. Critical independent thinking is considered essential in good work in these institutions, more important than mere assimilation of the facts or memorization of the profound or the trivial. In North America, unlike many Third World countries, it is generaily accepted that education has as much to do with molding the way people think as it does in providing them with specific technical training with which to pursue careers and obtain jobs. Those who are classically trained point out that this is at times at thie cost of some of the disciplined, detailed work essential for thorough analysis. However, this reservation is not very compelling when one thinks of the problems that planners face in development planning in the Third World. They are problems that quickly reach crisis proportions, where expeditious and sound investment of scarce public resources literally means life or death to poor people, and where, even if all the facts are not in or can never be obtained, decisions have to be made. In this context American pragmatism can permeate American academia in a useful way so as to augment an individual planners power to think in order to act, and to act expeditiously.

in crisis situations people trained to be able to ask the right questions, make broad leaps of conjecture, and span the gaps in knowledge become invaluable, and American universities appear to be more receptive to teaching these skills. In this teaching the use of qualitative methods plays an important role. Foreign students, particularly from Asia, are usually well trained in quantitative methods by the time 
they reach North American shores. They also consider quantitative methods as more legitimate and a "hard skill." In the face of this position, one, furthermore, shared by many US academics and students, it is a challenge to impress upon the student the alternative and complementary method of qualitative analysis that may allow for breakthroughs in thinking and understanding and thus suggest action that quantitative analysis alone might preclude.

I intend in this chapter to draw upon my personal experiences both as a graduate student and as a foreign-born academic teaching at a US university to illustrate the ways in which qualitative approaches, methods, and evaluations play a critical role in good graduate education for planners in general and why I think they are essential for a Third World student's growth. I will also elaborate why I believe the academic environment in the best US universities is congenial for teaching these skills and for developing a one-world approach to planning education.

\section{WHAT ARE QUALITATIVE METHODS?}

Planners use methods borrowed from many disciplines. These are usually modified and adapted to meet their needs to acquire and sift through many diverse information sources helpful in dealing with complex societal problems. The quantitative methods that planners use are well known, are well established in practice, and are acknowledged by most as tools of the planner's trade. In contrast to this, most planners also use qualitative methods, but these are rarely acknowledged. This is partly a consequence of the formative years of the planning discipline, when planning was promoted as an exercise in the application of technical, scientific rationality to societal problem-solving. The methods stressed were generally highly quantutative in the attempt to make planning appear to be more like the natural sciences. In the national planning of Third World countries after World War II, empiricism, economic modeling, and quantitative analysis dominated and were the ways of looking at social reality. But dissatisfaction with the limitations of this approach and the results achieved began to surface. Planners continued to be confronted by issues not amenable to quantitative analysis. By the early 1970 s there was a shift to micro-studies and complementary qualitative methods to augment planners' understanding of social systems. Qualitative methods responded to those aspects of planning practice that were found to be not readily amenable to quantifiction. They became even more valuable as planning shifted from physical/technical plan-making to policy analysis with a concern for human/ social/political systems. These systems were observed to operate in ways that were not easy to explain or comprehend in numerical terms. Theories fell short of explaining reality and informing interventions and qualitative methods were seen to offer some new insights and possibilities.

The need for qualitative methods in planning can succinctly be explained by (1) the time factor, the need to act when there is a general paucity of time available for deliberations; (2) the need to cope with data scarcity; and (3) the need to capture subjectivity in decision-making. I have elsewhere organized the qualitative methods 
used in planning in the following three catagories: methods to document and study built form; techniques to study human, societal interaction, studies of planning process and organizational structures[1]. Planning interventions of all three kinds occurred in Third World countries during the development decades that followed World War II. Initial interventions were made in large infrastructural projects, experience with which led to greater inquiry into the underlying social and institutional dynamics that shaped them[2]. This was followed by efforts to examine and change management and organizational structures to achieve more successful implementation and delivery of benefits as well as to set more attainable targets and to design more appropriate planning processes[3].

An extensive discussion of the reasons why planners use, yet underemphasize their reliance on, qualitative methods, or of the various qualitative techniques currently used in planning practice and in planning education, is beyond the scope of this chapter. Such discussions and accompanying bibliographies are available elsewhere[4]. However, it may be useful to note the relationship between qualitative and quantitative methods which have recently been described as follows[5]: "The term qualitative methods is sometimes misleadingly interpreted to mean that no quantification is involved. This is inaccurate. In qualitative methods observations are made, and often things are counted, mapped, charted, and/or analyzed. Evidence is gathered, not 'just intuited.' Furthermore, another inaccurate perception is that the uses of qualitative and quantitative methods are mutually exclusive, that there are some adversarial elements between the two approaches and that therefore a practitioner must be either a quantitative or a qualitative methodologist. This too is an inaccurate assumption. Not only are the methods not mutually exclusive, but they are rather, when properly used, mutually reinforcing and complementary"[6].

It is clear from the growing interest and experimentation, not just in the planning field but in diverse disciplines such as business management and clinical psychology, that a variety of essentially qualitative techniques such as nominal group, gaming simulation, strategic decision-making, and futuring are proving helpful in various professional practice situations. Recognition of their importance is paralleled by a growing awareness of the limitations of exercising only technical, scientific, linear thinking in problem-solving.

Many opportunities exist for using qualitative methods in educating master's and doctoral-level students in the context of a comparative approach that stresses planning in an inter connected and interdependent world. But there are also some problems, not the least of which is overcoming the initial resistance and discomfort associated with such "soft," that is, non-quantifying, work and approach. As mentioned earlier, qualitative methods do not imply no quantification; they just do not rely on it exclusively nor necessarily give it the highest priority. The accepiance of this approach can cause different problems for students at the master's as opposed to the doctoral level. In any case the pursuit and acceptance of a qualitative approach might be more sustainable in a US university than elsewhere, because of 
the evolution of the field of planning in this country. This point deserves some elaboration.

The field of urban and regional planning, as it has now evolved - distinct from the British town planning tradition, which largely dealt with physical design - is a particularly American development. Interdisciplinary work has, historically, tended to flourish in universities in the US. The frontier spirit of the country perhaps causes academics to be less entrenched in the classics. American universities such as Johns Hopkins and Chicago, although theoretically inclined, were among the first to be receptive to the applied aspects of fields such as law and engineering. The connection between theory and practice, the serious study of the consequences of practice, followed closely on the heels of this acceptance.

A presumption, radical for its time, was that dialogue between disciplines was important and should be of interest to the scholar. The Chicago School of Planning, blossoming for a brief period in the late fifties and early sixties, sparked off a wave of international interest in urban and regional planning. Urbanist sociologists from Chicago, such as Louis Wirth, emphasized the importance of socioeconomic understanding in planning and a movement away from intervening only in the physical, spatial realm. This was the time when, and the place where, it became an article of faith that what was happening in the less developed countries of the world was, and should be, of concern to American academia. The idea that one could plan development emerged in the post-World War II era of Rexford Tugwell and Walter Rostow. The discipline is particularly American and took a leadership role in attempting to integrate the facts about conditions abroad with the thinking that was current here[7]. Initial efforts in development planning were couched in terms of economic rationality and the arguments based on economic modeling and quantitative analysis. But first in practice and later in theory, these efforts accommodated social realities that could not be understood solely in those terms.

\section{A QUALITATIVE APPROACH TO PLANNING RESEARCH AND PRACTICE}

It became clear that in the theory and the techniques of, and the policy formulation in, an applied field such as planning value choices are made that transcend technical rationality. Subjectivity is involved in what may, at first glance, appear to be purely technical choices. In academic contexts, choices of areas to explore are unbounded by the constraints experienced in professional practice. The variety of problems that suggest themselves can be looked over, and those of most interest or significance, and those that a particular person is uniquely qualified to study, can be selected for attention. This is a luxury the practitioner can rarely exercise. The fact that the student can be allowed, even encouraged, to pursue this work, and reinforced intellectually for doing it, financially supported by grants to implement it, is to the credit of American universities and the scholars who help determine policy. The prevalent vision goes far beyond the immediate, pragmatic, and parochial. 
This characteristic of North American academia influenced my own demeanor when I went back to do field work in my native India. During preliminary consultations with local scholars on my arrival in India, an eminent Indian male professor of sociology advised me, when he realized that my study of rural change involved actually living in a village for a year or two, to reformulate the design so I could work on it while staying in an urban locale. His reason was that "lady students" are not suited to (the implication was, not safe in) the hardships of village life. Class and gender attitudes had raised their heads in Indian academia! It was well-meant advice, yet had I heeded it, by playing it safe along Indian conventions I might not have done anything really original. In fairness to this professor I should add that a quantitative understanding of the cultural context would suggest that this would be good advice for most Brahmin women scholars in India. However, had this professor done a qualitative assessment of the individual student before him, he might have chosen another tack. I was obviously influenced by the feminist discourse in the US and by the sense developed there that personal observations and exploration, not just quantification and a massaging of census figures, are important for the understanding of rural processes and problems. My approach was shaped by my status as a graduate student in the US, one, furthermore, for whom the arguments for a qualitative approach had been convincing.

Other Indian academics, V.M. Dandekar (no relation to me) and Sulabha Brahme at the Gokhale Institute, were less influenced by the prevailing academic norms, more receptive to my approach to the problem. They helped me attain my research objectives. Dr. Dandekar suggested villages I might visit and consider as possible sites and provided names of potential contacts in them. He arranged to have one of the Gokhale Institute's most experienced field researchers work in collaboration with me on the village study. I was generously offered the use of meticulously collected earlier surveys of some of these villages. Dr. Brahme discussed the research design in the terms I presented it, elaborated on its strengths and weaknesses from her experience of the Indian context, and suggested useful modifications that augmented the original research intent. I was fortunate to find the support of these and other maverick academics and researchers in India. But to find them it was important that I had returned to India with a developed and alternate vision of how I wanted to do research and what I wanted to examine. Fortified by their interest, I prevailed in my original plan and lived in the village. It wasn't easy but it wasn't impossible, and I did complete some fairly interesting work. What is perhaps as important is that the process of doing this work transformed me, and that, I believe, is what a good educational experience consists of, not only a retracing of well trodden paths but making new discoveries. I believe that academic institutions in the US and academics in them can be very important in encouraging precisely this. This may be their primary contribution, imparting to the student an ability to think in fresh and, one hopes, creative terms.

All wisdom in such matters is not embodied in all academics in North American universities. Many are in fact rather insensitive to Third World conditions and the reality of doing ficld work in them. I remember an American academic who critiqued a description of some of the methods I used in my in-depth 
study of Sugao village that explores urban-rural linkages in India[8]. I had described how I often entered into long, open-ended conversations with residents during the process of completing my survey of the village. It was my way of solving my own ethical dilemma about what I could and should give back to the people, many of them very poor, who were generously giving me their time, their energy, and their knowledge. I described the process as one in which we "entertained each other with stories, thus communicating rich information abcut our lives." My academic critic had responded to this with the comment that perhaps that was all we had achieved — "mutual entertainment" — and that "the truth" had escaped me. I had not followed "rigorous," "approved" methods of survey research. Controlled "probes" had not been used systematically in interviewing the whole population. The comment reflected a belief in value-free social science methods. I knew, as most people who have done field work in rural parts of the Third World do, that an essential part of getting information from people is to establish rapport and trust. One cannot do that by rigidly following the rules of "objective" information gathering described in survey techniques. The methods of anthropology and sociology, the techniques of qualitative methods such as participant observation have to be used if planners are to obtain good information from people who are illiterate or not able to communicate in the language of the generally urban and educated researcher. Many of the qualitative techniques designed to obtain such information have been developed in the US as urban planning has shifted from rational planning to advocacy planning and a social learning approach. Academia in the US is therefore a good environment to learn these skills and to come into contact with leading practitioners of the art.

Neither the students from North American countries nor those from developing ones are very comfortable with the idea of learning and using qualitative methods in research or in practice. Students from developing countries are generally skeptical about qualitative methods, which they consider a "soft skill." Learning to ask critical questions when posing and exploring the parameters of a problem is far less tangible than learning the techniques to manipulate data in the computer. There is a much stronger faith in the computer's ability to suggest "answers," and at the very least computer skills are tangible and "marketable" when one returns home. Many North American students share these perceptions, although they are relatively at ease with qualitative methods, and in questioning the basic premise of any idea, since this is a pedagogic style, starting from the lower tiers of the US education system. I do not denigrate the need to learn the so-called hard skills in planning, but there are many other, more qualified voices making the case for these. My point is that such "hard skills" and techniques will not yield effective policies if qualitative methods and understandings are not used to provide complementary and/or alternative insights. I believe that the orientation to qualitative methods can be taught well at major US universities and that different kinds of qualitative skills need to be taught at the master's and doctoral levels. 


\section{EDUCATING MASTER'S VERSUS DOCTORAL STUDENTS IN THE US UNIVERSITIES}

When evolving a one-world approach to teaching students of planning in the US it must be kept clearly in mind that teaching at the master's level and at the doctorai level present both different opportunities for interaction and growth, and different problems. These have to do with more than the mere difference in the number of years the students will be at the university. They are issues related to substantive content, theoretical underpinning, and areas of projected applications. Master's and doctoral students vary in their needs to acquire theoretical, analytical knowledge versus substantive and procedural skills. In addition, especially where foreign students are concerned, their long-term career objectives must be kept in mind. Some foreign students come here not intending to return home. Their objective is to remain in this country or to obtain work in international or multinational agencies, preferably prestigious ones such as the World Bank. Planning education needs to provide them with a flexible and broad set of skills and knowledge. This will enable them to become effective if they choose to return to their native counuries later. The issue of what should be taught, and how, has to be seriously addressed and an operating strategy has to be elaborated.

The issues that should be addressed when thinking about the education of master's-level planning students differ from those to be considered for doctorai studerits. At the master's level, the teaching of qualitative methods includes exercises that promote "learning through doing" through practical workshops and studio work. These often involve collection of information and "field work" at the city or county level. Interaction with the local community is often necessary. In this activity the foreign students normally lack the detailed political and cliltural understanding of place. They may initially be less resourceful in their ability to locate necessary sources of data and insight. This is perceived as a liability by the domestic students, particularly if group work is involved. This perception is reinforced if foreign students have difficulties expressing themselves in English or even if only their accents impede communications. In addition, some write poorly, and most usually lack knowledge of "Americanisms" and the ways in which professional communication occurs in this country.

Polarization and separation of foreign and domestic students can occur in the class, impeding the flow of ideas necessary for a comparative understanding of planning issues in an interdependent world. The faculty member has to be prepared to intervene quickly and as unobtrusively as possible in the early stages of group formation to prevent this. It might be pointed out that foreign students with good graphic skills, such as architects, are in demand in an incoming class of planning students since these skills are often scarce but needed in group projects. Architects, whether foreign or domestic, even though they generally lack developed writing skills, are perceived as useful additions to urban planning teams and are relatively easily integrated into the class. 
In running studio workshops, the professor must tie together and develop parallels between local and global issues. A case in point are the economic development processes discovered by the students through their investigations at the local level, which are compared and contrasted with those experienced at the global level by Third World countries. For example, small-town investments in high-tech industrial parks, and tax subsidies aimed at attracting industries to revitalize the local economy, can be compared with efforts to create jobs and encourage new industrial enterprises through tax-free zones and industrial enclaves in Third World countries. By introducing such connections in their materials, faculty members can foster a comparative one-world approach to development thinking. In my qualitative methods courses, one of the more successful themes at the master's level, facilitating such integration, has been an exploration of the ways in which a city can support the local small farm economy: a topic of current interest in Michigan but also of great relevance to students from Ghana, Yemen, and India. There is in addition a need to maintain an institutional "memory" of the work that has been done by past students, making that experience accessible to new students so that it can be elaborated and built upon by successive generations of foreign and domestic students.

Doctoral student training has to emphasize the conceptual, analytical skills to a greater extent than the procedural ones. It is very important to foster within the doctoral student the ability and independence to recognize, first of all, whether research is needed. He or she must be taught to argue a position persuasively and make clear the rationale underlying that position. An advanced doctoral student must be able to formulate a problem clearly and creatively and thus provide intellectual leadership. In the development of these attributes qualitative methods become extremely important because the individual is dealing with values and conflicts and these are not quantified - easily or at all.

The fact that this expectation of doctoral students is prevalent in the US universities but is not common in developing countries was quite forcefully brought to my attention when I was doing field work in India. I had computer-coded and tabulated my survey data and run initial tables and statistical analyses on the computer. A doctoral student who was putting the finishing touches to her dissertation at the prestigious Gokhale Institute of Politics and Economics commented that my doctoral degree work was now quite close to completion. All I needed to do now was to put a cover on the "number crunching" and I would be done. Her emphasis, and that of her institute, was primarily on quantitative analysis and analytic skills. I knew that was not true for me or my institute. Hard months lay ahead with John Friedmann and Peter Marris at UCLA to extrapolate meaning and significance from this infor-mation. The justification, the clarification, of why these numbers and observations were important, interesting, and relevant to theory building in development planning was just beginning. My doctorate would not be complete until I had satisfied them, and myself, of the merits of this work.

Research seminars in which a case study approach is taken are the usual format for illustrating commonalities and differences in countries of the Third 
World and between First and Third World contexts. These doctoral seminars function best when a good balance is achieved between opportunities for students to share their experiential knowledge (1) of the country they are studying and (2) of the logistical problems and dilemmas that present themselves when one is doing field research in the Third World. These can include, for example, data gaps, inaccurate data, data interpretation, appropriate research methods, and the questioning of ruling paradigms.

Often the presence of domestic students interested in the problems of certain minorities in the First World (e.g., poor blacks, the Inuit of Canada, American Indians) adds a transworld, comparative dimension to the class with little additional facilitation on the part of the professor. Also, the professor can require that students investigate topics and countries different from the ones they are primarily interested in to promote a broader understanding. The excellent libraries at large US universities and the existence of centers for area studies greatly facilitate this endeavor and can enrich the students' global one-world view. The teacher then tries to achieve a delicate balance in the format to allow for open-ended flows of communication regarding the specifics of places that the students know first hand and in depth; and the students extrapolate from a particular case to what is generalizable and cross-national in nature and central to the planning process. The professor must ensure that both of these activities occur.

In development planning this process of making connections between the reality of Third World life and the practice of planning, between the particulars of a case study and some theory that might be helpful in comprehension, is at its best an exhilarating experience. In these conversations, although the professor brings to the group expertise in particular theoretical areas and specific geographic contexts, his or her principal function is to understand the nuances of the situation presented by the student and to help to make the connections between the particular case and its parallels with the theoretical core. That is the challenge in teaching development, to help students make sense out of the complex and often confusing reality they are a part of by virtue of personal experience and observations and to suggest possible ways to think of acting and intervening.

Professors can be critical factors influencing what students learn and how they change. In addition, the ambience of the university, the caliber of fellow students, their values, and lifestyle can be even more significant. Both continuity and change can be fostered in the intellect of the foreign student if the academic is able to encourage the student to build on previous experience and to influence the constraints the university structure imposes on the student. For the students, the extent of their professors' knowledge of conditions in the Third World, in addition to their sympathetic understanding of the societies and cultures the students come from, are important factors in the type of work they are encouraged to produce, the research they manage to complete, and the adjustments they are able to make. With enough empathy, even when the student is developing research skills while doing doctoral research, the work can be honed to address conditions prevalent in the home country -- using and adapting methods and concepts developed here. 
Such an opporiunity offered in an American university allowed me to go back to India and reacquaint myself with my homeland, with its cities and its villages. But my approach to them was tempered by the approach I had learned in the US. This approach enabled me to make observations in a more structural, analytical fashion about processes in India that I had previously known only experientially.

Before doing research in a Third World context, however, foreign doctoral students and North American students who wish to work abroad have the problem of trying to work out preliminary pilot projects without being able to return home or travel abroad. Trying techniques out on US data and settings may or may not be suitable for this purpose. The faculty advisor has to be sensitive to this. The student should be encouraged to extend himself or herself in the pilot tests, but also to be alert to differences, expected or not, in the field. This brush with the way things are in the US is often conducive to fostering a one-world approach. Also, it becomes necessary to establish overseas contacts with host institutions whose faculty can advise and guide the student about local realities. The faculty member has to keep an open mind about listening to and evaluating the student's experience in the field and evaluating the research decisions that were made there.

\section{THE ACADEMIC ENVIRONMENT IN THE US}

In the US, development planning education that trains individuals to cope with Third World realities in some institutions de-emphasizes the teaching of nitty-gritty techniques to emphasize fostering of a mind-set that allows the individual creatively to formulate solutions to intersectoral problems. The ability to impart such skills in North American universities is continually questioned, particularly by academics and professionals in developing countries. Can relevant problem solving capabilities be taught, it is asked, outside the specific context of a particular country and a particular place? The lack-luster results of several decades of planning for development indicate a mismatch between the theoretical premises of the development field and the complex reality of life for people in the developing world. However, it is precisely in this important task, of identifying the mismatch and exploring the alternatives for action, that the North American academic context can be most useful. It is here where foreign students from all over the world, North American domestic students, foreign-born academics, and the US academics are involved in dialogue and inquiry. The multiple vision that results from this collaboration and work can be most effective and productive.

The characteristics of the intellectual climate in academic life in the US that bode well for this work are the possibilities for conversations, interactions, research, and project work with people for whom thinking is not work but rather a way of life. At the best institutions the academic world is one in which ideas are central, providing excitement and enjoyment. The perks of academic life are colleagues with liberal, tolerant, searching attitudes and willingness to question the conventional. They are the wealth and the strength of a system open and receptive 
to new ideas. These are the outstanding individuals who are not threatened by the challenges of outsiders but are accepting of, and even stimulated by, them. In such a context the foreign student and foreign-born academic can be perceived as an opportunity and a resource.

The intellectual atmosphere at these major universities in the US allows for deviation from some, and synthesis of other, ideas from different countries and cultures. Basic premises in the field can be questioned more easily, comparing international realities, than is possible in a university in a developing country. The proverbial melting pot is a reality in these North American universities that have a reputation for excellence. It is a context that brings together a truly international, experienced, articulate, and searching group of students. Participating, as a student or a professor, in an advanced research seminar in these universities is an experience in mutual learning, one that requires a qualitative understanding and approach on the part of both students and faculty. Not all US academics have an enlightened understanding of the realities of life in the Third World. Not all of them understand that a mix of qualitative and quantitative methods is essential to study these realities. Examples given earlier in this chapter in fact offer contradictory evidence. I merely claim that the better US universities offer the best potential for the development of such an understanding.

Extrapolation, conceptualization, comparisons, and contrasts with other countries are quite germane to the field of international development planning, and in this endeavor the American university has made a major contribution. The connections and ideas that resonate across international waters form a thick network, particularly well represented in the web of people affiliated with institutions such as the World Bank, USAID, and UNESCO. The relationship of academics and the practitioners in the realm of international development is complex and significant[9]. The more recent theoretical literature on development has pointed out that, in implementation, the discoveries of science are incorporated in the application of new technology and in the formulation of development strategies, and that the particular technologies promoted are very much part of the values of thuse who do the selection. In helping to inculcate the values of a one-world approach in their students, North American university educators can make a considerable contribution to international development work.

Given this dominance of academics and theoreticians in developing countries on development planning thinking, there are some pragmatic reasons why teaching and learning about a one-world approach to development planning may best be done in a US context. An effective critique and rebuttal of the choices made in Western-dominated or Western-influenced circles that formulate policy for international development can perhaps come only from those in the Third World who have made the journey from the developing world to the Oxfords, MITs, Harvards, and Michigans of the Western world. The impact of colonialism on the attitudes and world view of people from the Third World has been extensive. Counter models reflecting a stronger Third World perspective but fully cognizant of the Western world viewpoint can perhaps best be articulated by those who have "a 
foot in both worlds." These are people in command of the language of the First World and its planning jargon, able to understand the mind-sets and value systems that underlie both First and Third World ways of thinking. Such an understanding and approach might permit the synthesis and integration that would be convincing to all sides. A one-world approach to planning education may offer the best opportunity to train such people.

\section{CONCLUSION}

The use of qualitative methods in planning in developing countries as well as in developed countries has become essential. Qualitative methods are perhaps most helpful in contexts in which data are few and time is short, and where subjectivity in decision-making must be factored into the analysis. These are certainly characteristics of most Third World planning environments. As I have pointed out elsewhere, qualitative methods are not simpler or less expensive or easier methods, although in some situations they well might be. They are different, and they deal with and provide an understanding of different aspects of the planning problem. This chapter has not attempted to describe the nature and characteristics of qualitative measures, presuming that that would be redundant for the reader. Rather, it has tried to describe why and when the qualitative approach to education seems to have great promise in communicating a one-world approach to planning education. Imparting competence with qualitative methods is essential if one is to enable graduate planning students to perceive the planning problems of the world in the comparative framework of a one-world reality. At the master's as well as doctoral levels, students have to learn to make the leaps of conjecture as well as the rational, technocratic integration needed to allow this to happen. There is a great need on the part of the faculty both to practice qualitative approaches to the education of students and to teach the methods. The US university is in an enviable position to attempt this task.

\section{NOTES}

1. See Hemalata C. Dandekar, 1986, "Some uses and potentrais of qualitative methods, Journal of Planning Education and Research, 6, 1: 42-49.

2. An early and significant work that stimulated considerations of "project fit with institutional and societal context" was A.O. Hirschman's Development Projects Observed. Washington, D.C., Brookings Institution, 1967.

3. Donald Schon's work on organizations and David Korten's work on process have been significant.

4. For a listing of some of the significant work in qualitative methods in planning, see Hemalata C. Dandekar, "Some uses and potentials of qualitative methods." See also the offerings by Sage publications in the series on Qualitative 
Research Methods, edited by John Van Maanen, including the publication of Jerome Kirk and Marc L. Muller, Reliability and Validity in Qualitative Research, Vol. 1, October 1985.

5. See Hemalata Dandekar, "Qualitative methods" in: Urban Planning, J.C. Snyder and A.J. Catanese, eds., McGraw-Hill, New York, 1988.

6. This viewpoint is elaborated by various authors in W.J. Filstead, ed., Qualitative Methodology, Markham, Chicago, 1970. This is an edited collection of papers, directed primarily at issues and problems encountered by sociologists using qualitative methods. In the editor's words the purpose of the book is "to provoke those who measure everything and understand nothing." What is suggested is the need for more inductive theory. In the introduction the term "qualitative methodology refers to those research strategies, such as participant observation, in depth interviewing, total participation ... which allow the researcher to obtain first hand knowledge about the empirical social world in question. Qualitative methodology allows the researcher to (get close to the data) thereby developing the analytical, conceptual, and categorical components of explanation from the data itself - rather than from the preconceived, rigidly structured, and highly quantified techniques that pigeonhole the empirical social world into the operational definitions that the researcher has constructed" (p. 6). The need and the importance of a marriage of qualitative and quantitative methodology in the field of sociology are articulated by Morris Seldiatch in a chapter entitled "Some methodological problems of field studies" (Filstead, 1970, pp. 217-231).

7. For a personalized description of these early beginnings of planning thoughts in the US, see John Friedmann, "Encounters" and "Precursor: Karl Mannheim," in Retracking America, Rodale Press, Emmaus, Pennsylvannia, 1973, revised 1981, pp. i3-48.

8. See Hemalata C. Dandekar, Men to Bombay, Women at Home: Urban Influence on Sugao Village, Deccan Maharashtra, India. 1942-82, Center for South and Southeast Asia, University of Michigan, Ann Arbor, 1986.

9. Some of the complexities of these connections are described in Hemalata C. Dandekar, "On communications and their lack in international development planning,"Discussion paper no. 2, University of British Columbia, Vancouver, September 1982. 